\title{
Discussion on Teaching Method of Electronic Technology based on MOOC
}

\author{
Guo Panfeng \\ China Three Gorges University College \\ Yichang, China \\ gpf1226@163.com
}

\author{
Zhao Shenghui \\ China Three Gorges University College \\ Yichang, China \\ $84237641 @ q q . c o m$
}

\begin{abstract}
After the emergence of MOOC, it has been the impact of the University Theory Teaching and stimulated the reform of College Teaching. The concept of MOOC is analyzed in this paper. This paper also describes the impact and significance of MOOC in the teaching of electronic technology. And then, the teaching status of electronic technology course is analyzed. In the last, this paper discusses the teaching methods of the basic course of electronic technology based on MOOC and the opening of the course. In the end, the article summed up electronic technology basic course teaching reform conception diagram based on MOOC.
\end{abstract}

Keywords-MOOC; electronic technology; teaching; course work

\section{INTRODUCTION}

The ways of all kinds of reform are emerging with the reform of higher education. Taking the University as an example, the course construction reform of the course group as the unit has become a means of the current teaching reform. Since last year, the college has carried out dozens of course construction projects and the electronic technology basic courses as an important basic course of electrical engineering. The intensity of the course is more obvious. So, how to build? How to reform? This paper will discuss the teaching method of electronic technology foundation course in the course construction.

\section{THE CONCEPT AND SIGNIFICANCE OF MOOC}

MOOC is short for the course of large-scale network open course (Massive Online Open Course), and it is free open network course for the public. MOOC has begun to study in 2007. And with the rapid expansion of the number of learners in the MOOC program, MOOC this course mode has caused the attention of distance education, open education and the whole education industry. In addition, MOOC will integrate social networks, a field of experts and online resources available to integrate. Through various forms of social media to participate in the discussion, thinking, sharing resources. The course is generated in the exchange of participants [1].

The course of electronic technology is one of the most important basic courses in the environment of MOOC theory. It is the first to carry out the reform of the teaching method of the course, including the theory teaching method, the teaching method, the operation way and so on. At present, the basic form of MOOC two curriculum model, one of which is the University as the center which more and more become the hot spot to talk about and implementation. On the one hand, this model can improve the efficiency of the course, and on the other hand, the impact of the traditional theory teaching methods. In this environment, it is necessary to change the teaching method of the existing electronic technology foundation course.

\section{THE CHARACTERISTICS OF ELECTRONIC TECHNOLOGY BASIC COURSE}

Electronic technology foundation course is divided into two parts of the theory teaching and practice teaching. The two parts each have their own characteristics.

\section{A. Theory teaching features}

The characteristics of electronic technology basic course of theory teaching are mainly embodied in the concept, basic knowledge, rich in content, profound theories, etc. In terms of intellectual capacity, electronic technology basic theory teaching content includes digital electronic part and analog electronic part. Every part has strong integrity, theoretical and abstractness, analog electronic parts, especially for the internal structure of the device analysis particularly strong abstractness. The entire content witnessed a gradual development gradually in-depth, the characteristics of the clear lines. In addition, it needs on the basis of circuit principle and physical courses, there is a clear physical concept, reflecting the strong theoretical.

However, from the point of view of the entire contents of the electronic technology foundation course, spanning physics, electronics, electromagnetics, modern test and control technology, content is wide, scattered and mixed; Look from the signal involved, weak current signal control high voltage signal, and a more abstract concept of the magnetic field and magnetic circuit. All of these, to cause students to learn this course, coupled with the less class hour, so that the students generally feel difficult when learning this course.

\section{B. The practice teaching characteristic}

Electronic technology foundation course is to carry out the contest of electronic design competition such as indispensable 
important basic course, each part of the theory can be through the practice to understand, verify, consolidate, through practice training of basic skills, strengthen the understanding of theory link, get the perceptual knowledge, in practice, also can train students to understand and correct use of the commonly used electronic instrument, to be prepared for the future practical work.

Electronic technology foundation course of practice can put this to use in our daily life, help to stimulate students' learning interest, let students really feel the importance of specialized courses and practical. However, within the limited class hours and under the experimental condition, the practice is hard to cover, also difficult to play its proper role and effect.

\section{CURRENT Situation OF EleCtronic TECHNOLOGY BASIC COURSE}

Electronic technology basic courses include analog electronics and digital electronics. It is one of the basic courses in the major of electrical engineering and computer science, which has the characteristics of strong theory. The content level and knowledge of the course are progressive, and the progressive of the device to the system. At present, the teaching of the basic course of electronic technology is as follows:

In terms of teaching methods, most of the current teaching materials in our school take the original outline. This will have some problems that the selection of materials is often a few years ago or even ten years ago. The old teaching material may not keep pace with the times in the rapid development of the electronics in these years. In addition, Multi-Media has improved the status of more content, less school time, but also brought some problems. It makes the original theory of strong and difficult to understand the curriculum is even worse in the case of some teachers in the case of the screen. The students will have distaste for the boring classroom, some even go to play truant. In addition, the content of the teacher in the classroom is often based on mature and basic. For example, we focus on the "transistor, thyristor" and the basic MOSFET tube, but now MOSFET is more common, so the theory and the actual failure to achieve coordination.

Students learn the knowledge of electronic technology based only on the classroom. It will affect the students to follow the electrical professional course of study if out of the classroom. However, the emergence of the MOOC, micro courses and so the network may be able to change this situation. The change of classroom role will be the students.

\section{The Reform of The TEACHING Methods BASEd ON MOOC}

\section{A. The reform of the teaching of electronic technology based on $M O O C$}

Make clear the goal, shorten the hours, weaken the ability and skills, pay more attention to the teaching process of students comprehensive application of knowledge and ability to learn independently in the whole teaching reform. In the teaching theory, take the student as the main body, with the teacher as the leading combined with the MOOC network teaching, put forward "interest guiding, guidance method, induced advantage" teaching ideas, teaching process pay attention to and inspire students to think about the problems, stimulate the enthusiasm of the students, the formation of teacher-student interaction, left to the students more space to think, to develop their self-learning ability and learning ability. In practice teaching, it can emphasize the practice method and the practice process, guide students to analyze problems and solve problems, and improve their practical ability and innovation ability. To promote team form to carry out more complex experiments, to exercise the students learn from each other, and the team spirit of unity and cooperation. Make full use of modern teaching methods to achieve three-dimensional teaching, improve teaching efficiency and teaching effect [2]. The use of rich network resources, the construction of the course website, achieves the online Q \& A, including the course of the basic information and resources, to provide students with three-dimensional information.

On the methods of assessment, reconstruct the evaluation system of teaching quality, pay more attention to the teaching process quality control, increase performance assessment of the proportion of (theory course usual results for 40\%), outstanding students comprehensive application of knowledge ability and innovation ability, guide the student to realize three transformations: change oriented learning for autonomous and research learning, change the exam oriented results to pay attention to learning process and change calculation ability is a comprehensive ability to use knowledge. In the course of the implementation of the examination and education, the separation of the exam, the examination and the unified examination papers, in order to evaluate the teaching effect and improve the teaching quality. Teaching methods and means of reform and renewal play a good role for students' self-learning ability and the quality of the training [4].

\section{B. The creation of electronic technology foundation course based on MOOC}

Course assignment is to require students to complete a certain amount of work with a certain amount of teaching form for a certain course which is a research based on the characteristics of the curriculum, the workload and the students' characteristics. In the case of MOOC impact theory, the emergence of the course work is bound to be a more appropriate form of teaching reform. It can have the following ideas and measures about how to implement [3].

In a MOOC environment, explore the of electronic technology course work based on electronic technology based on key course construction projects and combined with the requirements of teaching reform [5]. It includes writing the outline, the topic of work scope and requirements, the completion of the method and course assignments evaluation system and so on. Formulate the overall plan about the implementation plan for the work of the basic course of electronic technology after course construction group discuss or participate in a certain reference value of the relevant meeting and so on after comprehensive consideration of the college's resources and students' ability. Course work in the form of a variety of forms, the way students taking can give full play to the students' autonomy and innovation. College or 
school will provide corresponding conditions, but in the end the examination and evaluation of the course assignments to strictly, evaluation forms in the form of the form or report, or reply form and so on.

In the process of implementation, it can take the following measures: (1) It improve the efficiency of the classroom through strengthening the diversification of teacher teaching means, such as the conversion of thinking, the use of MOOC, micro courses network resources and teaching form, so as to make the initiative of the students to be fully played out. It has more help to the opening of the course. (2) Getting a comprehensive understanding about whether the college is influenced by MOOC and network resources in the course of electronic technology [6]. Determine the degree of acceptance of the current teaching methods and the ability to complete the course work. (3)Understand demands for reform comprehensively. Discuss, group, implement the course work and check results of it in the characteristic and special class. Complete of the purpose of cultivating students' innovation ability, practical ability and innovative talents with international view in the course of course work.

\section{Based on the electronic technology of MOOC curriculum reform conception}

Comprehensive this MOOC based on electronic technology basic course teaching reform and teaching method of discussion, this paper concluded the following results.

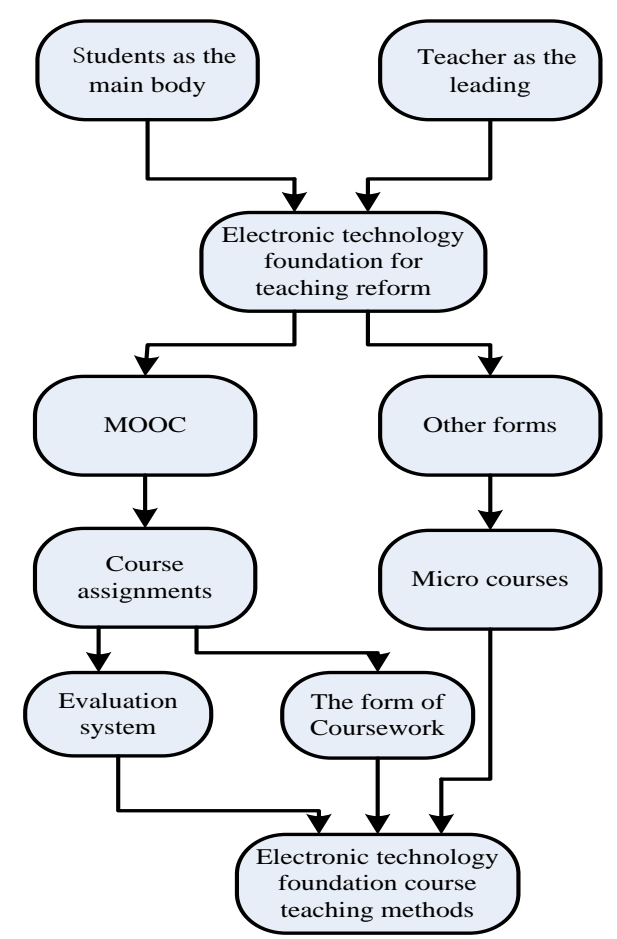

Fig.1 the figure of teaching method based on the MOOC

\section{CONCLUDING REMARKS}

More and more colleges and universities use MOOC which is a kind of large-scale network open class. And it has become the hot topic and the source of the teaching reform in the major colleges and universities. Based on MOOC this kind of network open class and teaching status of electronic technology foundation course in our school, his article draws a conclusion that it is suitable for the teaching reform of the basic course of electronic technology in our school. Especially, the opening of the course work may be more suitable for this kind of network course and discussed the measures to open the course work, in order to make the electronic technology basic course teaching more suitable for the development of the university under the network open class.

\section{REFERENCES}

[1] Wang Ying,Zhang Jinlei \& Zhang Baohui. MOOC: Characteristics Analysis Based on Typical Projects and Its Enlightenment [J]. Journal of Distance Education, 2013,4 :67-74

[2] Sun Jinping, Li Dan. Based on the pattern of MOOC course teaching reform [J]. Fujian computer, 2014,05:58-59.

[3] Wu Nanzhong. Understand the internal logic course - MOOC teaching design [J]. Electrochemical education research, 2015,03:29-33.

[4] Wang Wenli. The development of the MOOC and its impact on higher education [J] . Jiangsu higher education, 2013(2):53-57.

[5] Xu Ming, Long Jun. Based on the concept of MOOC network information security series curriculum teaching reform $[\mathrm{J}]$. Journal of higher education research, 2013,36(3):16-19.

[6] Li Hua, Gong Yi, Ji Juan. Design MOOC oriented learning management system framework $[\mathrm{J}]$. Modern distance education research, 2013(3):28-33. 